\title{
Public Confidence in the Health Care System 1 Year After the Start of the Ebola Virus Disease Outbreak — Sierra Leone, July 2015
}

\begin{abstract}
Wenshu Li, PhD ${ }^{1}$; Mohamed F. Jalloh, MPH${ }^{1}$; Rebecca Bunnell, PhD ${ }^{1}$; Yvonne Aki-Sawyerr ${ }^{3}$; Lansana Conteh, MPH ${ }^{4}$; Paul Sengeh, MSc ${ }^{2}$; John T. Redd, MD ${ }^{1}$; Sara Hersey, $\mathrm{MPH}^{1}$; Oliver Morgan, $\mathrm{PhD}^{1}$; Mohammad B. Jalloh, $\mathrm{MPH}^{2}$; Ann O’Leary, $\mathrm{MPH}^{5}$; Erin Burdette, $\mathrm{MPH}^{6}$; Kathy Hageman, $\mathrm{PhD}^{7}$
\end{abstract}

Ensuring confidence in the health care system has been a challenge to Ebola virus disease (Ebola) response and recovery efforts in Sierra Leone (1). A national multistage clustersampled household survey to assess knowledge, attitudes, and practices (KAP) related to Sierra Leone's health care system was conducted in July 2015. Among 3,564 respondents, $93 \%$ were confident that a health care facility could treat suspected Ebola cases, and approximately $90 \%$ had confidence in the health system's ability to provide non-Ebola services, including immunizations, antenatal care, and maternity care. Respondents in districts with ongoing Ebola transmission ("active districts") and respondents with higher educational levels reported more confidence in the health care system than did respondents in nonactive districts and respondents with less education. Active districts were the focus of the Ebola response; these districts implemented intensified social mobilization and communication efforts, and established district response centers, Ebola-specific health care facilities, and ambulances. Greater infrastructure and response capacity might have resulted in higher confidence in the health care system in these areas. Respondents ranked Ebola and malaria as the country's most important health issues. Health system recovery efforts in Sierra Leone can build on existing public confidence in the health system.

The 2014-2015 Ebola outbreak in Guinea, Liberia, and Sierra Leone exposed many of the public health challenges these countries face, particularly the need for and lack of a strong health infrastructure (2). Ebola control efforts were hampered by lack of understanding about Ebola transmission, mistrust and fear of health facilities and providers (3), delays in seeking care, or refusal to seek care (4). Sierra Leone's Ebola recovery and health security strengthening efforts depend upon willingness of a population to seek care and trust in that care. An assessment of public attitudes can help develop interventions to address these barriers and build public trust in the health care system. To better understand health care-seeking practices and perceptions of the health care system in Sierra Leone during the Ebola outbreak, the Sierra Leone Ministry of Health and Sanitation and CDC partnered with FOCUS 1000, a Sierra Leone-based nongovernmental organization,* and other stakeholders to conduct the KAP survey in July 2015.

\footnotetext{
*http://focus1000.org.
}

The national cross-sectional household survey used multistaged cluster sampling, with probability of selection of primary sampling units (clusters) proportional to their size. Ninety-one clusters were sampled, and 20 households were selected from each cluster using systematic random sampling. Because of their influential role in household decisions and practices, heads of households were prioritized for interviewing. Anticipating that a majority of the household heads would be older men, interviewers randomly selected a second survey participant from each household (either a woman of any age or any other person aged 15-24 years). To ensure reliable districtlevel estimates, active districts ${ }^{\dagger}$ (areas in which a confirmed Ebola case had been reported during the preceding 42 days) were oversampled. A weighting factor was applied to each record to adjust for selection probability at the district level.

Trained data collectors used an open source application for digital data collection (OpenDataKit ${ }^{\S}$ ) installed on WiFi/4Genabled tablet computers. The survey included open-ended questions about participants' expectations regarding a health care facility's treatment of suspected Ebola cases. Participants' free responses were coded into predetermined response categories. Participants were also asked to rate their confidence regarding Ebola care, non-Ebola illness care, immunization services, and antenatal and maternity care using a 3-point Likert scale with 0 representing "not at all confident" and 2 representing "very confident." Confidence in the health care system was quantified by summarizing frequency, mean score, and standard deviation. Two questions asked about health care-seeking behaviors (willingness to take an ambulance if feeling ill today [yes/no] and willingness to take an ambulance if feeling ill after the outbreak is declared to be over [yes/no]). Participants rated how important it was for their health care system to treat and prevent certain diseases, using a 5-point Likert scale, with 1 representing "not important at all" and 5 representing "very important."

Data were stored on a secure web hosting server and imported into SPSS version 22 for analysis. Results were stratified by demographics, and analysis of variance (ANOVA)

\footnotetext{
$\dagger$ Active districts were Western Urban Area (including the capital of Freetown), Western Rural Area, and Kambia and Port Loko districts (both in the Northern Province); Nonactive districts included Bombali, Koinadugu, Tonkolili, Kailahun, Kenema, Kono, Bo, Bonthe, Moyamba, and Pujehun districts. ${ }^{\S}$ https://opendatakit.org/.
} 
testing was used to examine group differences. Mean scores and standard deviations for importance were calculated for each health issue. Because participants' ratings on importance of treating and preventing each health issue were all $>3$ on a 5-point Likert scale, the responses resulted in a negative skewed distribution; the data were normalized before conducting parametric statistical analysis. Repeated measure ANOVA was conducted to examine the differences in ratings for each health issue. Least significant difference posthoc analysis was conducted to examine the pairwise differences and rank importance levels.

Among the 3,640 persons approached by data collectors, 3,564 (98\%) participants from 1,782 households consented to take part in the survey (two participants per household). The final survey included 1,774 (49.8\%) males and 1,790 $(50.2 \%)$ females; the participants' average age was 35 years (standard deviation $=15)$.

Overall, the majority of participants had positive responses about their expectations of a health care facility's treatment of suspected Ebola cases: $69.8 \%$ believed that patients suspected of having Ebola would receive care, and $56.0 \%$ believed that the health care facility could definitely cure a patient's Ebola (Table 1). The proportion of participants who reported they would ride in an ambulance today if they felt ill (63.3\%) was similar to the proportion who said they would do so once the Ebola outbreak was declared over (65.8\%) (Table 1).

The majority of the participants were either "very confident" or "somewhat confident" about the health care system's ability to treat Ebola, to treat non-Ebola diseases, to provide children with immunizations safely, and to provide antenatal and maternity care (Table 2). Respondents who resided in active districts expressed more confidence in the health care system than did respondents in nonactive districts. Respondents who had secondary or higher education also

\begin{tabular}{|c|c|}
\hline Expectations of treatment at health care facilities* & No. (\%) \\
\hline $\begin{array}{l}\text { They will take care of him/her (rehydrate, give medicines/ } \\
\text { food, and monitor status) }\end{array}$ & $2,488(69.8)$ \\
\hline They will definitely cure the person from Ebola & $1,996(56.0)$ \\
\hline I don't know/not sure/no response & $161(4.5)$ \\
\hline Others & $59(1.7)$ \\
\hline $\begin{array}{l}\text { They will find a way to kill the patient so that he/she doesn't } \\
\text { spread Ebola to others }\end{array}$ & $37(1.0)$ \\
\hline $\begin{array}{l}\text { They won't be able to do anything for him/her and he/ } \\
\text { she may die there }\end{array}$ & $36(1.0)$ \\
\hline They will be turned away & $5(0.1)$ \\
\hline \multicolumn{2}{|l|}{ Health care-seeking behavior } \\
\hline Willing to ride in an ambulance if feeling ill today & $2,257(63.3)$ \\
\hline $\begin{array}{l}\text { Willing to ride in an ambulance if feeling ill when Ebola } \\
\text { was declared over }\end{array}$ & $2,344(65.8)$ \\
\hline
\end{tabular}

* Open-ended question that was back-coded into predetermined responses. reported more confidence about Ebola treatment and child immunization (Table 2) than did respondents with primary school or lower education.

A repeated measure ANOVA identified significant differences among ranking the importance of health issues in Sierra Leone, $(\mathrm{p}<0.000)$. A follow-up pairwise comparison indicated the rank of importance as follows: Ebola (mean Likert score $=4.40)$, malaria (3.92), diarrheal disease (3.74), tuberculosis (3.45), and pneumonia (3.43).

\section{Discussion}

In 2010, before the start of the 2014-2015 Ebola outbreak, Sierra Leone was making progress toward its Millennium Development Goals, including stabilization of human immunodeficiency virus prevalence at $1.5 \%$ and reductions in child and maternal mortality compared with 2000-2005 levels (5). However, the protracted Ebola epidemic might have negatively affected some of those gains. For example, reported measles vaccination coverage declined from $99 \%$ in January 2014 to $76 \%$ in July 2014, just 2 months into the outbreak (6). By July 2015, Ebola incidence in Sierra Leone had declined significantly since peaking in November 2014; at the time of this survey, there was widespread expectation that the country's Ebola case count would soon reach zero. Approximately $90 \%$ of respondents reported at least some level of confidence in the health care system, and approximately half reported being very confident in Ebola care, non-Ebola care, immunization services, and antenatal and maternity services. Although much remains to be done to strengthen the health care system in Sierra Leone, these findings suggest public confidence in the system. Building on this confidence through community engagement and communication could complement and accelerate health care system recovery efforts. Strengthening the health care system's infrastructure and building capacity, including increasing the number of health workers, might help ensure that increases in demand for services are met (7).

Although the majority of survey participants had at least some level of confidence in the health care system, confidence level varied by geographic location and education. For example, confidence of participants from Eastern Province, where the first case of Ebola was identified, and Western Area, where the largest number of Ebola cases occurred, was higher than in other regions. Kailahun and Kenema districts in Eastern Province were the initial epicenters of the outbreak and had the first two treatment centers in the country. Witnessing Ebola patients being treated and surviving might have contributed to higher levels of confidence among residents in Eastern Province. During January-July 2015, Western Area, Kambia, and Port Loko (the active districts) 
TABLE 2. Level of confidence in health care capacity, by province/area and level of education — National Knowledge, Attitudes, and Practices Survey, Sierra Leone, July 2015

\begin{tabular}{|c|c|c|c|c|c|c|}
\hline \multirow[b]{2}{*}{ Characteristic } & \multirow[b]{2}{*}{ No. } & \multirow{2}{*}{$\frac{\text { Not at all confident }}{\%(95 \% \mathrm{Cl})}$} & \multirow{2}{*}{$\begin{array}{c}\text { Somewhat confident } \\
\%(95 \% \mathrm{Cl})\end{array}$} & \multirow{2}{*}{$\frac{\text { Very confident }}{\% \%(95 \% \mathrm{Cl})}$} & \multicolumn{2}{|c|}{ Confidence level scores } \\
\hline & & & & & $\mathrm{M} / \mathrm{SD}$ & $\mathrm{p}$-value \\
\hline \multicolumn{7}{|c|}{ Capacity to treat Ebola } \\
\hline \multicolumn{7}{|c|}{ Province/Area* } \\
\hline Western & 798 & $6.0(5.3-8.2)$ & $35.0(31.5-38.4)$ & $59.0(55.5-62.6)$ & $1.53 / 0.61$ & $<0.000$ \\
\hline Northern & 1,740 & $6.7(3.0-5.9)$ & $44.1(41.3-46.9)$ & $49.1(46.3-51.9)$ & $1.42 / 0.62$ & \\
\hline Eastern & 471 & $4.4(8.4-12.7)$ & $37.5(34.1-40.8)$ & $58.1(54.7-61.5)$ & $1.54 / 0.59$ & \\
\hline Southern & 555 & $10.5(6.1-7.8)$ & $44.4(41-47.8)$ & $45.0(41.6-48.5)$ & $1.34 / 0.62$ & \\
\hline \multicolumn{7}{|l|}{ District type $^{\dagger}$} \\
\hline Active & 1,237 & $6.8(5.4-8.2)$ & $35.0(32.3-37.7)$ & $58.2(55.9-60.9)$ & $1.51 / 0.62$ & 0.000 \\
\hline Nonactive & 2,327 & $7.0(6.0-8.0)$ & $43.9(41.9-45.9)$ & $49.1(47.1-51.1)$ & $1.42 / 0.60$ & \\
\hline \multicolumn{7}{|l|}{ Education } \\
\hline None & 1,303 & $7.9(6.4-9.4)$ & $42.1(39.4-44.7)$ & $50.0(47.3-52.8)$ & $1.42 / 0.63$ & 0.008 \\
\hline Primary & 734 & $6.3(4.5-8.0)$ & $43.4(39.8-47.0)$ & $50.3(46.7-54.0)$ & $1.44 / 0.61$ & \\
\hline$\geq$ Secondary & 1,519 & $6.3(5.1-7.5)$ & $38.4(36.0-40.9)$ & $55.3(52.8-57.8)$ & $1.49 / 0.61$ & \\
\hline Total & 3,564 & $6.9(6.1-7.7)$ & $40.8(39.2-42.4)$ & $52.3(50.7-54.0)$ & $1.45 / 0.62$ & - \\
\hline \multicolumn{7}{|c|}{ Capacity to treat non-Ebola illness } \\
\hline \multicolumn{7}{|c|}{ Province/Area* } \\
\hline Western & 798 & $5.3(3.7-7.0)$ & $24.0(20.9-27.1)$ & $70.6(67.3-73.9)$ & $1.65 / 0.58$ & $<0.000$ \\
\hline Northern & 1,740 & $5.4(4.2-6.7)$ & $33.3(30.6-35.9)$ & $61.3(58.6-64.1)$ & $1.56 / 0.60$ & \\
\hline Eastern & 471 & $3.7(2.4-5.0)$ & $30.4(27.2-33.5)$ & $65.9(62.7-69.2)$ & $1.62 / 0.56$ & \\
\hline Southern & 555 & $6.1(4.4-7.7)$ & $39.2(35.8-42.6)$ & $54.7(51.3-58.2)$ & $1.49 / 0.61$ & \\
\hline \multicolumn{7}{|l|}{ District type $^{\dagger}$} \\
\hline Active & 1,237 & $5.0(3.8-6.2)$ & $26.3(23.8-28.8)$ & $68.7(66.1-71.3)$ & $1.64 / 0.58$ & 0.000 \\
\hline Nonactive & 2,327 & $4.1(3.3-4.9)$ & $37.7(35.7-39.7)$ & $58.2(60.2-35.3)$ & $1.54 / 0.58$ & \\
\hline \multicolumn{7}{|l|}{ Education } \\
\hline None & 1,303 & $5.7(4.4-6.9)$ & $32.9(30.4-35.5)$ & $61.4(58.8-64.0)$ & $1.56 / 0.60$ & 0.278 \\
\hline Primary & 734 & $4.8(3.2-6.3)$ & $32.1(28.7-35.4)$ & $63.2(59.7-66.7)$ & $1.58 / 0.58$ & \\
\hline$\geq$ Secondary & 1,519 & $4.8(3.7-5.9)$ & $31.1(28.8-33.5)$ & $64.1(61.6-66.5)$ & $1.59 / 0.58$ & \\
\hline Total & 3,564 & $5.1(4.4-5.8)$ & $32.0(30.4-33.5)$ & $62.9(61.3-64.5)$ & $1.58 / .59$ & - \\
\hline \multicolumn{7}{|c|}{ Capacity to safely provide children with immunizations } \\
\hline \multicolumn{7}{|c|}{ Province/Area* } \\
\hline West & 798 & $3.6(2.2-4.9)$ & $22.5(19.5-25.6)$ & $73.9(70.7-77.1)$ & $1.70 / 0.53$ & 0.000 \\
\hline North & 1,740 & $5.7(4.4-7.0)$ & $34.7(32.0-37.3)$ & $59.7(56.9-62.4)$ & $1.54 / 0.60$ & \\
\hline East & 471 & $1.7(0.8-2.6)$ & $28.3(25.2-31.4)$ & $70.0(66.8-73.2)$ & $1.68 / 0.50$ & \\
\hline South & 555 & $6.2(4.5-7.9)$ & $47.8(44.4-51.3)$ & $46.0(42.5-49.4)$ & $1.40 / 0.60$ & \\
\hline \multicolumn{7}{|l|}{ District type $^{\dagger}$} \\
\hline Active & 1,237 & $5.4(4.1-6.7)$ & $25.9(23.5-28.3)$ & $68.6(66.0-71.2)$ & $1.63 / 0.58$ & 0.000 \\
\hline Nonactive & 2,327 & $4.2(3.4-5.0)$ & $38.5(36.5-40.5)$ & $57.3(55.3-59.3)$ & $1.53 / 0.58$ & \\
\hline \multicolumn{7}{|l|}{ Education } \\
\hline None & 1,303 & $5.4(4.2-6.7)$ & $34.2(31.7-36.8)$ & $60.3(57.7-63.0)$ & $1.55 / 0.60$ & 0.023 \\
\hline Primary & 734 & $4.2(2.8-5.7)$ & $34.2(30.8-37.6)$ & $61.6(58.1-65.1)$ & $1.57 / 0.57$ & \\
\hline$\geq$ Secondary & 1,519 & $3.6(2.7-4.6)$ & $32.8(30.4-35.1)$ & $63.6(61.2-66.0)$ & $1.60 / 0.56$ & \\
\hline Total & 3,564 & $4.4(3.7-5.1)$ & $33.6(32.1-35.2)$ & $62.0(60.4-63.6)$ & $1.58 / 0.58$ & - \\
\hline
\end{tabular}

See table footnotes on next page.

experienced intensified social mobilization, enhanced surveillance, and scale-up of treatment facilities; this more developed infrastructure and capacity to respond to Ebola in the active districts might have engendered higher levels of confidence in those areas. Another possible reason for higher confidence in the active districts might be related to the strengthened infection prevention and control efforts aimed at decreasing the high rate of Ebola infection among health care workers early in the epidemic (8). The higher levels of confidence in the health care system to treat Ebola and provide childhood immunizations among participants with higher education levels might be a consequence of their having more knowledge and fewer misconceptions about available services. In addition, participants with higher levels of education might have better access to health service information, because radio discussions about health care messages are sometimes conducted in English rather than local languages, which might exclude persons with less education. A 2014 KAP survey in Nigeria also found education level to be positively related to the participant's knowledge, attitudes, and practices regarding Ebola (9). 
TABLE 2. (Continued) Level of confidence in health care capacity, by province/area and level of education - National Knowledge, Attitudes, and Practices Survey, Sierra Leone, July 2015

\begin{tabular}{|c|c|c|c|c|c|c|}
\hline \multirow[b]{2}{*}{ Characteristic } & \multirow[b]{2}{*}{ No. } & \multirow{2}{*}{$\frac{\text { Not at all confident }}{\%(95 \% \mathrm{Cl})}$} & \multirow{2}{*}{$\begin{array}{c}\text { Somewhat confident } \\
\%(95 \% \mathrm{Cl})\end{array}$} & \multirow{2}{*}{$\begin{array}{c}\text { Very confident } \\
\%(95 \% \mathrm{Cl})\end{array}$} & \multicolumn{2}{|c|}{ Confidence level scores } \\
\hline & & & & & $\mathrm{M} / \mathrm{SD}$ & $p$-value \\
\hline \multicolumn{7}{|c|}{ Capacity to provide ante-natal and child birthing care } \\
\hline \multicolumn{7}{|c|}{ Province/Area* } \\
\hline West & 798 & $3.8(2.4-5.2)$ & $23.9(20.8-27)$ & $72.3(69.0-75.5)$ & $1.69 / 0.54$ & 0.000 \\
\hline North & 1,740 & $6.1(4.7-7.4)$ & $34.3(31.7-37)$ & $59.6(56.8-62.3)$ & $1.54 / 0.61$ & \\
\hline East & 471 & $2.1(1.1-3.1)$ & $30.4(27.2-33.5)$ & $67.5(64.3-70.8)$ & $1.65 / 0.52$ & \\
\hline South & 555 & $5.7(4.1-7.3)$ & $47.0(43.6-50.5)$ & $47.3(43.8-50.7)$ & $1.42 / 0.60$ & \\
\hline \multicolumn{7}{|l|}{ District type $^{\dagger}$} \\
\hline Active & 1,237 & $6.2(4.9-7.5)$ & $26.0(23.6-28.4)$ & $67.8(65.2-70.4)$ & $1.62 / 0.60$ & 0.003 \\
\hline Nonactive & 2,327 & $4.6(3.7-5.5)$ & $35.3(33.4-37.2)$ & $60.1(58.1-62.1)$ & $1.55 / 0.58$ & \\
\hline \multicolumn{7}{|l|}{ Education } \\
\hline None & 1,303 & $5.8(4.5-7.0)$ & $33.6(31.0-36.2)$ & $60.6(58.0-63.3)$ & $1.55 / 0.60$ & 0.251 \\
\hline Primary & 734 & $4.1(2.7-5.5)$ & $34.9(31.5-38.4)$ & $61.0(57.5-64.5)$ & $1.57 / 0.57$ & \\
\hline$\geq$ Secondary & 1,519 & $3.9(2.9-4.9)$ & $33.9(31.5-36.3)$ & $62.2(59.7-64.6)$ & $1.58 / 0.57$ & \\
\hline Total & 3,564 & $4.6(3.9-5.3)$ & $34.0(32.5-35.6)$ & $61.4(59.8-63.0)$ & $1.57 / 0.58$ & - \\
\hline
\end{tabular}

Abbreviations: $\mathrm{Cl}=$ confidence interval; Ebola = Ebola virus disease; $\mathrm{M}=$ mean; $\mathrm{SD}=$ standard deviation.

* Western Area includes Western Rural and Western Urban districts; Northern Province includes Bombali, Kambia, Koinadugu, and Port Loko, and Tonkolili districts; Eastern Province includes Kailahun, Kenema, and Kono districts; Southern Province includes Bo, Bonthe, Moyamba, and Pujehun districts.

${ }^{\dagger}$ Active districts: districts with active Ebola cases (Western Areas, and Kambia and Port Loko in Northern Province). Nonactive districts: districts with no Ebola active cases (Bombali, Koinadugu, Tonkolili, Kailahun, Kenema, Kono, Bo, Bonthe, Moyamba, and Pujehun districts).

The Ebola epidemic overwhelmed an already fragile health care delivery system (4) and reduced the availability of services for endemic health concerns such as malaria and diarrhea (10). Scientific models have suggested that untreated malaria cases resulting from overwhelmed health care systems could have contributed to $>10,000$ additional malaria-attributable deaths in West Africa during the Ebola epidemic (10). Survey participants recognized malaria as the most important health concern after Ebola, underscoring the importance of interventions to mitigate malaria morbidity and mortality during future Ebola response and recovery activities.

The findings in this report are subject to at least four limitations. First, responses were self-reported and could be subject to social desirability bias. Second, the survey was conducted at a time when Ebola response capabilities and infection rates varied by geographic area; areas with stronger Ebola response capabilities might have generated higher confidence in the health care system. Third, the survey measured confidence levels in the heal th care system using a 3-point Likert scale, whereas a 5-point Likert scale was used to measure importance levels of treating and preventing different diseases. Using the same scale to measure confidence levels and importance levels in the survey would be preferred. Finally, there was no baseline assessment for confidence levels in the health care system and importance levels of treating and preventing different diseases before the Ebola epidemic, so differences in confidence by geographic area and education cannot be attributed to the Ebola outbreak.

\section{Summary}

What is already known about this topic?

Public mistrust and fear based on misconceptions regarding health care system facilities and providers increased during the Ebola virus disease (Ebola) epidemic in Sierra Leone, and health care system usage rates declined sharply. Sierra Leone's Ebola recovery and global health security strengthening efforts require willingness of citizens to seek care and place trust in that care.

What is added by this report?

A majority of participants in a knowledge, attitudes, and practices survey conducted after approximately 15 months of an Ebola epidemic in Sierra Leone expressed at least some confidence in the health care system's ability to treat patients suspected to have Ebola, and $>90 \%$ reported confidence that the health care system could also provide non-Ebola services, including immunizations, antenatal care, and maternity care. Respondents from areas with active Ebola transmission had higher confidence in the health care system, as did respondents with higher education levels. Respondents ranked Ebola and malaria as the most important health issues for Sierra Leone.

What are the implications for public health practice?

Understanding factors contributing to public confidence in the health care system can help develop education and health promotion campaigns. Public confidence in the health care system to deliver basic services provides a foundation on which to build a restored and improved post-Ebola health system in Sierra Leone.

Understanding the public's confidence in the health care system can help develop public education and health promotion campaigns. The public's base of confidence provides a foundation on which to build a restored and improved health system in Sierra Leone. 
${ }^{1}$ Division of Global Health Protection, Center for Global Health, CDC; ${ }^{2}$ FOCUS 1000, Freetown, Sierra Leone; ${ }^{3}$ Sierra Leone National Ebola Response Centre; ${ }^{4}$ Sierra Leone Ministry of Health and Sanitation; ${ }^{5}$ Division Of HIV/ AIDS Prevention-Intervention Resources \& Support, National Center For HIV/AIDS, Viral Hepatitis, STD, \& TB Prevention, CDC; ${ }^{6}$ Division of Foodborne, Waterborne, and Environmental Diseases, National Center for Emerging and Zoonotic Infectious Diseases, CDC; ${ }^{7}$ Division of Global HIV and TB, Center for Global Health, CDC.

Corresponding author: Wenshu Li, kuq5@cdc.gov, 404-553-8916.

\section{References}

1. Nabarro D. Ebola will not be gone in any country until it is gone from every country. 136th executive board special session on Ebola. Geneva, Switzerland: World Health Organization; 2015. http://www.who.int/ mediacentre/events/2015/eb136/speech-david-nabarro/en/

2. Coyle RM, Harrison HL. Emergency care capacity in Freetown, Sierra Leone: a service evaluation. BMC Emerg Med 2015;15:2-10. http:// dx.doi.org/10.1186/s12873-015-0027-4

3. Alexander KA, Sanderson CE, Marathe M, et al. What factors might have led to the emergence of Ebola in West Africa? PLoS Negl Trop Dis 2015;9:e0003652. http://dx.doi.org/10.1371/journal.pntd.0003652
4. Elston JW, Moosa AJ, Moses F, et al. Impact of the Ebola outbreak on health systems and population health in Sierra Leone. J Public Health (Oxf) 2015;27:fdv158. http://dx.doi.org/10.1093/pubmed/fdv158

5. Government of the Republic of Sierra Leone. Millennium Development Goals progress report. Freetown: Government of Sierra Leone; 2010. http://www.sl.undp.org/content/sierraleone/en/home/library/ $\mathrm{mdg} / 2010$-sierra-leone-mdg-progress-report/

6. UNICEF. In Sierra Leone, vaccinations another casualty of Ebola. New York: UNICEF; 2014. http://www.unicef.org/infobycountry/ sierraleone_76892.html

7. Chowell G, Nishiura H. Transmission dynamics and control of Ebola virus disease (EVD): a review. BMC Med 2014;12:196-211. http:// dx.doi.org/10.1186/s12916-014-0196-0

8. Kilmarx PH, Clarke KR, Dietz PM, et al. Ebola virus disease in health care workers-Sierra Leone, 2014. MMWR Morb Mortal Wkly Rep 2014;63:1168-71.

9. Iliyasu G, Ogoina D, Otu AA, et al. A multi-site knowledge attitude and practice survey of Ebola virus disease in Nigeria. PLoS One 2015;10:e0135955. http://dx.doi.org/10.1371/journal.pone.0135955

10. Walker PG, White MT, Griffin JT, Reynolds A, Ferguson NM, Ghani AC. Malaria morbidity and mortality in Ebola-affected countries caused by decreased health-care capacity, and the potential effect of mitigation strategies: a modelling analysis. Lancet Infect Dis 2015;15:825-32. http://dx.doi.org/10.1016/S1473-3099(15)70124-6 